\title{
Bowl-shaped Hyperbolic Glass Curtain Wall Construction Technology
}

\author{
Luo Zhenglin, Che Zhiyan*, Zhang Haibin, Huang Dong \\ China Construction Shenzhen Decoration Co., Ltd., Shenzhen, China
}

Email address:

7959025@qq.com (Che Zhiyan)

${ }^{*}$ Corresponding author

\section{To cite this article:}

Luo Zhenglin, Che Zhiyan, Zhang Haibin, Huang Dong. Bowl-shaped Hyperbolic Glass Curtain Wall Construction Technology. Engineering and Applied Sciences. Vol. 4, No. 5, 2019, pp. 111-117. doi: 10.11648/j.eas.20190405.14

Received: August 2, 2019; Accepted: September 18, 2019; Published: September 30, 2019

\begin{abstract}
In the curtain wall work of China Construction Optics Valley Star Project H Block Headquarters Office Building, the treasure bowl in the atrium is the bowl-shaped hyperboloidal glass curtain wall, which is composed of hyperboloidal diamond-shaped glasses. It is difficult to install the glasses of various dimensions because the installation process is very complicated, thus being a thorny problem for this project. Based on the project case, this paper makes a summary and analysis of the construction process and technical key points and discusses how BIM technology is applied for modeling and material processing of this project. Moreover, it also explains the technical control points for the major procedures such as measurement and setting-out of control points, measurement verification, fabrication of tire frame, hyperbolic base keel welding, base element lifting of steel truss, installation and locating of hyperbolic steel truss base, installation of support point clamps, installation of hyperboloidal diamond-shaped glass. Finally, by utilizing the advanced technical means and scientific construction measures, this project solves the thorny problem and guarantees the installation accuracy and quality. The BIM technology and the method for controlling the base keel deformation and absorbing the deviation of structural deform adopted in this project are of great significance as reference for similar projects.
\end{abstract}

Keywords: Bowl Shape, Hyperboloid, Glass Curtain Wall, Construction Technology

\section{Project Introduction}

China Construction Optics Valley Star Project H Block Headquarters Office Building has a construction area of $80,000 \mathrm{~m}^{2}$ with 19 stories above ground and 2 stories underground. Its main structure is a concrete framework, with a hemispherical reinforced concrete shape in the lobby atrium, which is about $25 \mathrm{~m}$ high. The bowl-shaped façade is a hyperbolic glass curtain wall system located at the 4th and 5 th floors with a height of about $14.4 \mathrm{~m}$. The radius of the top plane of the bowl is $13.1 \mathrm{~m}$, and that of the bottom plane is $6 \mathrm{~m}$ (see Figure 1). The base steel of the glass curtain wall uses the $\varnothing 121 \times 6$ arc welded steel pipes with fluorocarbon coating on the surface. The glass is $8 \mathrm{FT}+2.28 \mathrm{SGP}+8 \mathrm{FT}$ hyperboloid diamond-shaped ultra-clear laminated glass with the dimension: $1200 \times 1400 \mathrm{~mm}$. The maximum element weight is about $68 \mathrm{~kg}$.

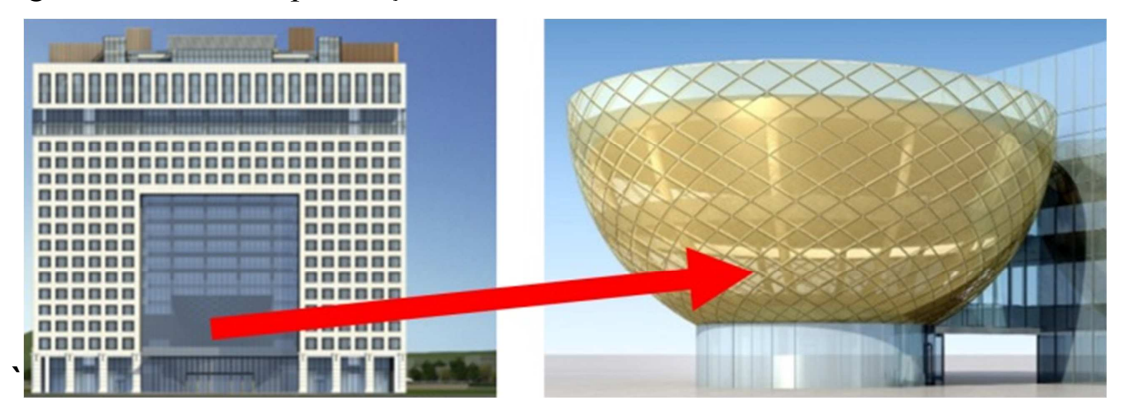

Figure 1. The architectural effect and location. 
Compared with the conventional glass curtain wall construction, the panel glass of the bowl-shaped hyperbolic glass curtain wall system of this project is hyperboloid diamond-shaped glass [1], which has varied dimensions and encounters difficulty in ordering. Difficulties also lie in measurement and setting out for the curtain wall construction and accurate installation and locating of the elements. It is risky to lift the elements and install the curtain wall due to the special shape and difficult to control construction safety. The curtain wall design must control the deformation of the keel at the base, and also effectively absorb the structural deformation and installation deviation [2].

\section{Principle of Construction}

The data are summarized for analysis after measurement verification and data acquisition. In line with the actual coordinates on site, the BIM software is applied to build an actual site structure model. The distance between the curtain wall and the structure in the drawing is adjusted to meet the requirements for the curtain wall installation, and also those for the structural safety and appearance [3]. Division, statistics, collection and sorting of the model elements are carried out to extract the machining dimension of each element, particularly arc-shaped element at the corner [4]. Through analysis by the BIM software, the radius of the element arc is measured, and then the elements are flattened to extract their unfolded dimension for ordering and machining [5].

The tire frame is installed before the base keel. Check after installation of tire frame, and assemble the keel after the hyperboloid meets the requirements. Following the installation of the base keel and point support clamps, the entire base and clamps need to be measured. If they are not compliant with the measurement requirements, an adjustment should be made to the item until the required technical parameters of the hyperboloid are met [6]. The glass is moved manually below the installation positions, installed with the platform of scissors and hoisted by the manual hoist.

\section{Key Construction Technologies}

\subsection{Measurement and Setting out}

\subsubsection{Preparation for Measurement}

Control points provided by the general contractor are reviewed. The review process is verifying another coordinate value by any two coordinate values. The completed civil structures are inspected to first determine the elevation $\pm 0.000 \mathrm{~m}$ and the position of the center of circle. The actual radius of each floor is measured with the center of circle. The structural deviation is obtained [7]. The data of structural measurement should be promptly fed back to the designers, who provide the technical parameters of the hyperboloid and the control network diagram (base and glass) according to the measurement reference of this project, for installation of field base and surface.

With the technical parameters of the hyperboloid and the control network diagram, the control points are measured and set out. According to the technical parameters of the hyperboloid and the accuracy requirements of the control network diagram, the measuring and setting-out factors of the control points include the distances between each interior angle of the octagon and two points. In order to ensure that there is a self-check effect, a coordinate measurement is added in the measuring and setting-out factors to review the distance between two points [8].

\subsubsection{Measuring and Setting-out Process of Control Points}

First, the testing station of instruments are set according to the points handed over by the general contractor; then the instruments are placed at points $1 \sim 8$ for measuring traverse distance and interior angle (see Figure 2); and finally, the control point coordinates are calculated.

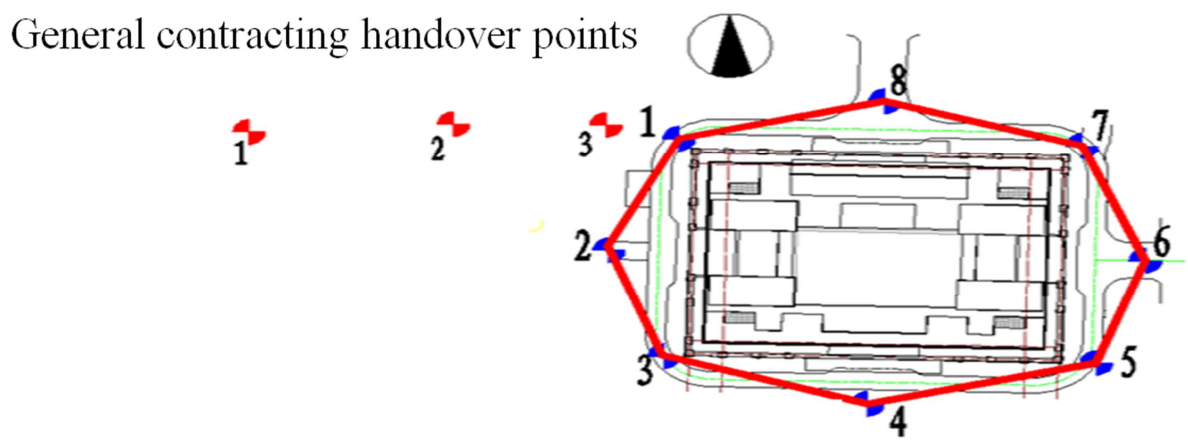

Figure 2. Schematic of general contracting control points and curtain wall control points.

\subsubsection{Measurement Verification}

The exterior curtain wall uses the hyperbolic diamond-shaped glass, which has very high requirements for the pedestal installation and dimension processing of glass. Reflectors (see Figure 3) should be attached to the intersection of the network structure during verification. They are observed with the total station. Then the three-dimensional verification data in the total station are exchanged with those in the computer, thus converting data to be points on the drawings. After plotting of the resulting drawing, it is 
compared with the original drawing to analyze the points with structural deviation and find the weakest position. The measurement and setting-out are also necessary for the installation of the hyperbolic glass clamps. The accurate position of a three-dimensional point is set out in the $3 \mathrm{D}$ space. It is difficult and low efficiency. In order to simplify what is complicated, 3D must be transformed to 2D [9]. The elevation must be determined first for finding the derivative of the elevation. The coordinate $(X, Y)$ of the clamp is set out. For example, the elevation line is set out on the structural surface of the 4th, 5th and 6th floors first, and then the mathematical relationship between polygon and curve at the same horizontal elevation may be established.

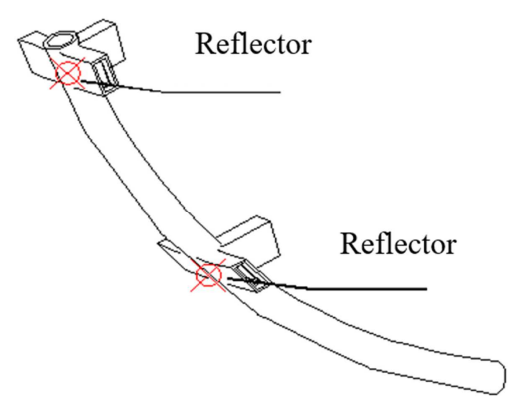

Figure 3. Reflectors.

\subsection{Base Keel Installation}

\subsubsection{Fabrication of Tire Frame}

Prior to the installation of the base keel, in order to ensure that the overall effects and the actual installation data are consistent with the drawings, firstly the tire frame must be fabricated. In the factory, the outer arc dimension of each point of the tire frame should be obtained according to the model drawing requirements. The installed tire frame is reviewed and the keel may be assembled only after the hyperboloid meets the requirements [10].

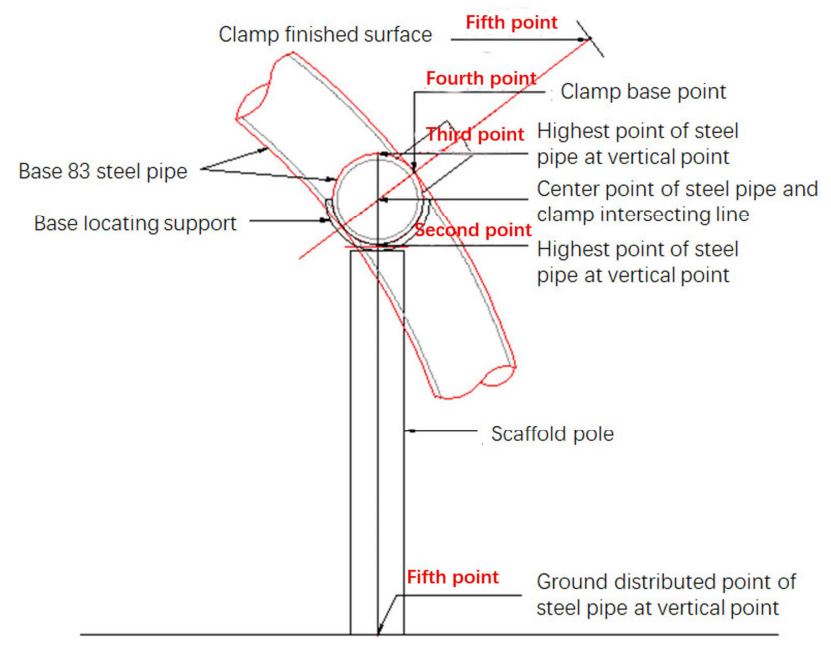

Figure 4. Locating of points.

By design, a one-fourth model is intersected on the model drawing. The model is rotated to be the bird's view. The pole distribution on the plane is vertically located on the ground according to the projection, and obtain the point of the pole on the ground, points of steel pipe and pole, vertical highest point of steel pipe, point of clamp and steel pipe, and external point from clamp to glass. These five points are used for locating (see Figure 4).

The positions of points should be corrected constantly during the tire frame erection process, to ensure that each point is at the position on the model drawing. After assembly, the whole truss is corrected (see Figure 5). Other allowable deviations must meet the specifications and design requirements.

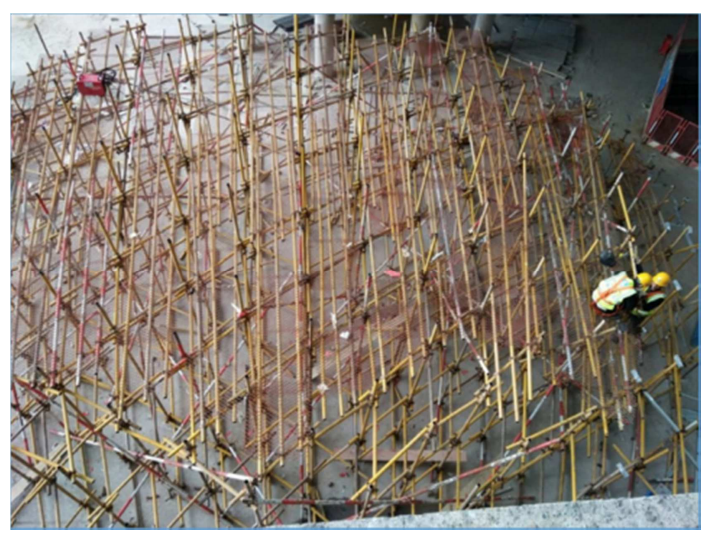

Figure 5. Installation of tire frame.

\subsubsection{Hyperbolic Base Keel Welding}

After installation of the tire frame, firstly the upper steel pipe keel is installed according to the keel elevation (see the blue line in the figure). Following the installation, the elevation is checked and the radius is located. When the requirements are met, the keel locating line is set out on the tire frame and then all keels in one direction are completed on the tire frame pursuant to the locating line (see the red directional line in the drawing). They are firstly spot-welded and then fully welded after check. After full welding, the keel positions are checked again. Correction should be made if there is any deviation. The keel intersecting point in another direction is set out on the completed keels, and these keels are installed. They are firstly spot-welded. After the temporary installation of all keels, the total station is utilized to check the base. Full welding is conducted after they meet the requirements for the technical parameters of the hyperboloid and the control network diagram. The welding slag is removed after full welding, and then check whether the weld seam quality meets the design requirements [11].

\subsubsection{Base Element Lifting of Steel Truss}

Through calculation, there are certain variables during the hoisting of the base steel keel. The variable at the lifting point is $5 \mathrm{~mm}$ and the bottom variable is $10 \mathrm{~mm}$. Therefore, these variables need to be controlled in the process of installation and locating. The lifting should be strictly subject to the calculated points.

When lifting, bind according to the lifting requirements and hang the drag rope (see Figure 6). Firstly, lift the steel truss to 
$1 \mathrm{~m}$ high above the tire frame. Steel pipes are mounted on the tire frame to form a simple slideway. Lift up the base close to the bowl structure with two manual hoists to assist at the rear end. When the structure blocks the lifting of the base steel truss, the manual hoists at the rear end pull back the base steel truss until the front end can be lifted. During lifting, the rear end relaxes slowly and slides on the slideway. When the rear end leaves the slideway, the drag rope is used to control the sway of steel truss.

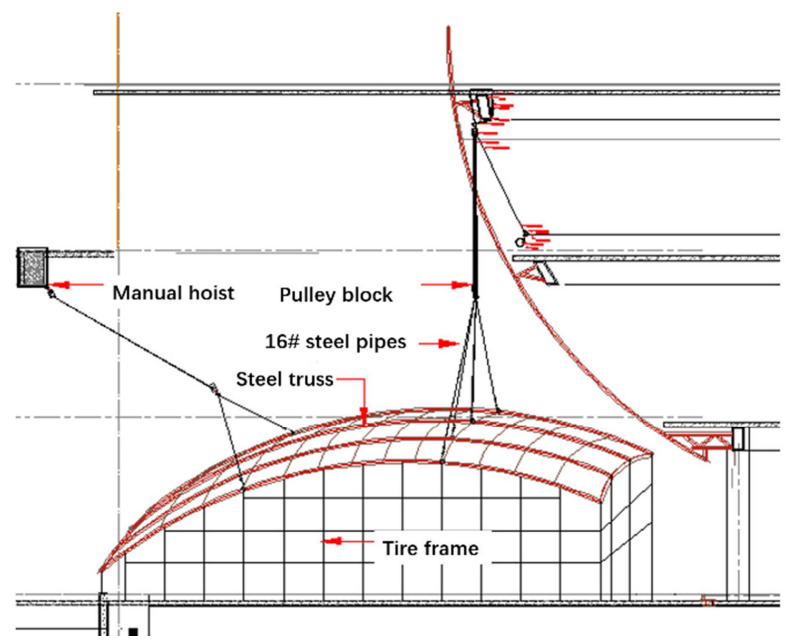

Figure 6. Schematic of binding before lifting.

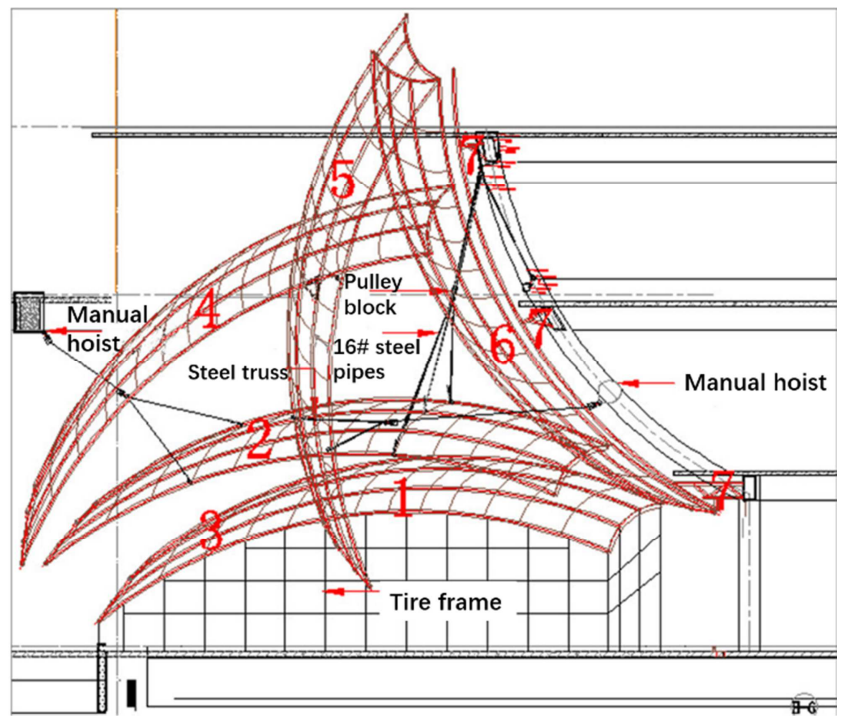

Figure 7. Schematic of base keel lifting.

The manual hoists move the steel truss backward to ensure the smooth rise of the front steel truss.

When the steel truss is perpendicular, the manual hoists are mounted on the fourth floor and fixed with the binding strips to prevent abrading the fireproof coating on the steel structure surface. The manual hoists retract the steel truss towards the bowl structure, and the upper pulley block continues to lift. Then, the drag rope needs to be controlled to avoid swaying of the steel truss. When the direction of manual hoists is being changed, the steel truss should feel the force on the tire frame and should not hang in the air.
For putting the steel truss at the proper location, according to the height required by the installation, the upper pulley block slowly lifts down the steel truss, and the manual hoists assist in retracting and locating (see Figure 7).

Then, the three-dimensional line for coordinate control is determined and then fixed by an adapting piece after the requirements are met. The bottom of the adapting piece is welded first, then the middle and upper portions [12]. In this process, the total station is used to control the standard locations, and the jack and manual hoists are utilized for adjusting the radius variable.

Joint assembly: After temporary fixation of the four frames, the joints are assembled and then proceed to the next procedure (see Figure 8).

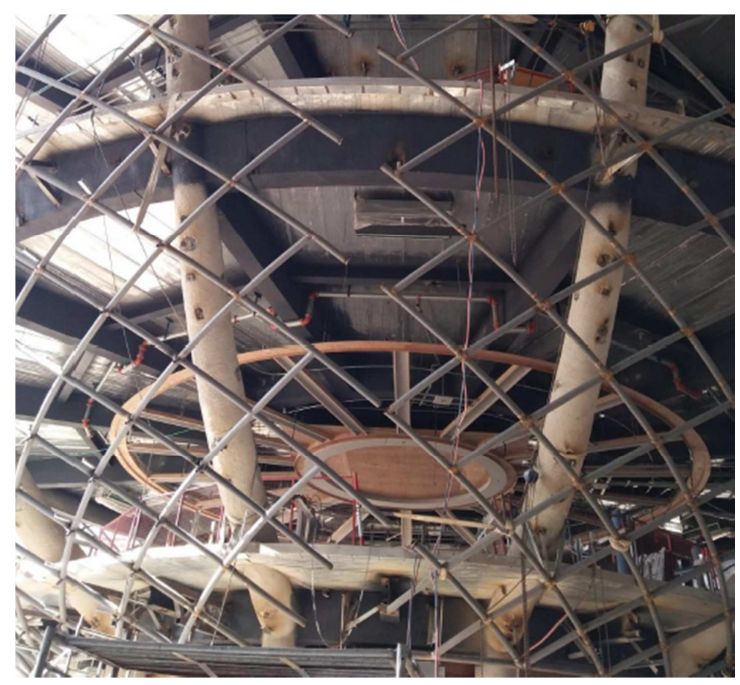

Figure 8. Joint assembling.

\subsubsection{Installation and Locating of Hyperbolic Steel Truss Base}

There are certain variables during lifting. Thus, during installation, the center support point must be fixed first to ensure that the center conforms to the horizontal elevation on the drawing [13]. The upper and lower support points are temporarily fixed by binding so that the steel truss may release the variables. When the upper and lower support points are fixed, the total station is used for tracking. Pressure over the upper portion may lead to a smaller radius and a lower height, and the natural force at the lower portion may lead to a larger radius and a greater height. Upon fixation, the upper and lower portions are stretched by manual hoists, and the total station is utilized for controlling the curvature radius of the claw. After locating, the three-dimensional line for coordinate control is determined for adjustment and then fixed by an adapting piece after the requirements are met. In this process, the total station is used to control the standard locations, and the jack and manual hoists are utilized for adjusting the radius variable. After installation, the truss should be promptly measured and corrected [14].

\subsection{Installation of Support Point Clamps}

During the installation of the clamps, they must be located 
and numbered first. According to the numbering and point data (see Figure 9), the total station is utilized for setting-out and locating of the clamps, and the auxiliary materials are used to enable accurate locating. A circle of auxiliary angle steel is welded around the perimeter of the structure, and then the mathematical relationship between polygon and curve is established at the same horizontal elevation. The position of angle steel in CAD is measured by the total station. Intercept the straight-line distance of clamps and draw a perpendicular line to the structural plane, and the intersecting point with the structural plane is the locating point of the clamp. After locating the clamp, the relationship between four sides of the clamps and the horizontal and vertical directions should also be determined to ensure that the angles between arcs at the four sides of the clamps are consistent.

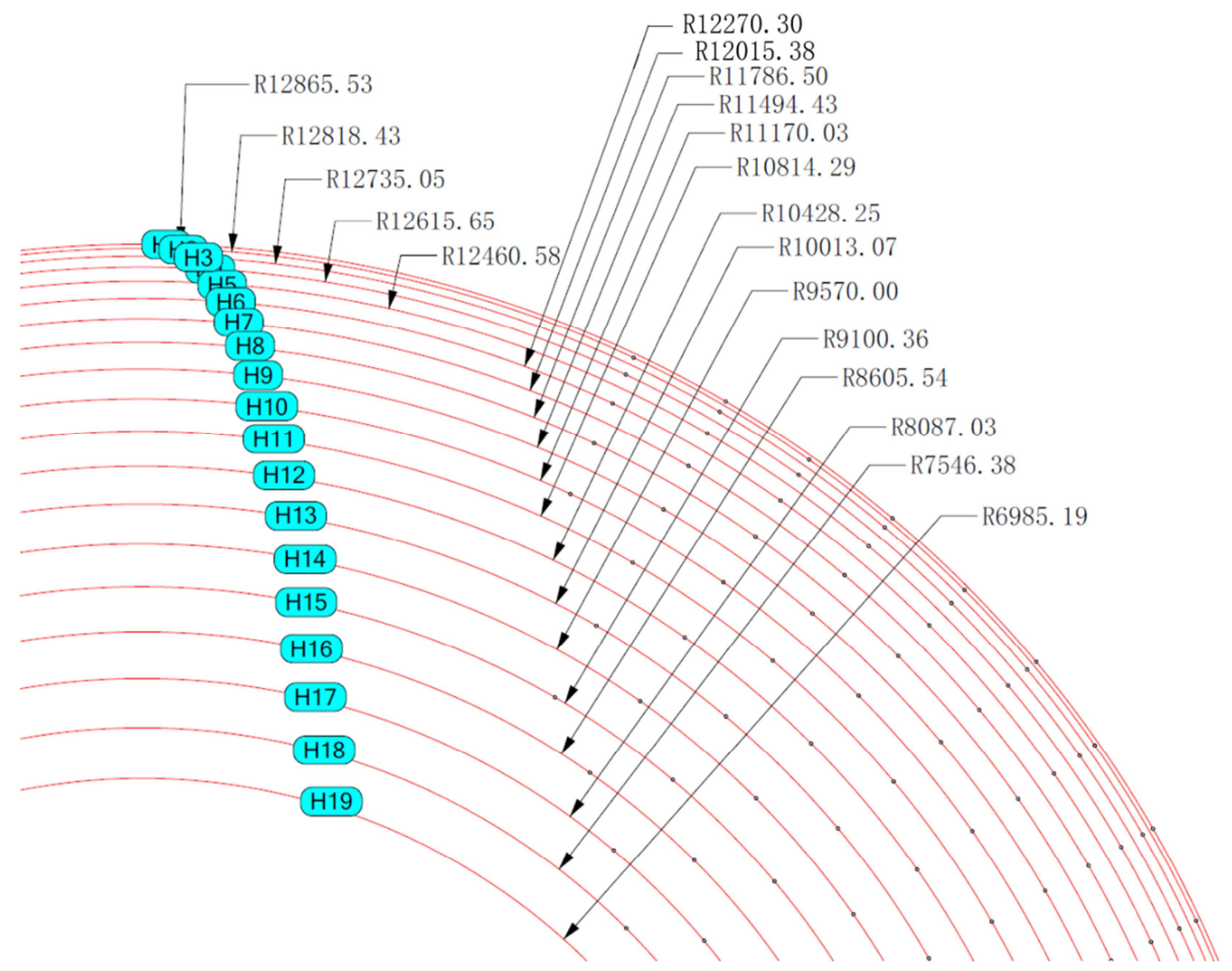

Figure 9. Schematic of rear-end locating of clamps.

\subsection{Overall Remeasurement and Adjustment}

The hyperbolic glass of this project has very high requirements for the installation accuracy. It is critical to smoothly install glass. After completing the installation of the base keel and point support clamps, the entire base and clamps need to be measured. If they are not compliant with the measurement requirements, an adjustment should be made to the item until the required technical parameters of the hyperboloid are satisfied.

\subsection{Installation of Hyperbolic Diamond-shaped Glass}

Aiming at the characteristics of the system glass, the machinery and equipment are made full use of for installation. After the glass arrives at the construction site, the quality inspectors, foreman and installation team leader should carry out $100 \%$ testing on the surface quality, nominal dimension and radian of the glass, and use the glass edge stress detector for sampling inspection of the glass tempering. The glass is installed from up to down and adjusted floor by floor. It is lifted by the electric hoist and nylon packing strip to the installation platform for locating and installation (see Figure 10). The construction steps are detailed as follows:

Installation of sliding guide rope and electric hoist $\rightarrow$ adjustment and tightening guide rope $\rightarrow$ commissioning and testing of electric hoist $\rightarrow$ glass ready for lifting $\rightarrow$ lifting $\rightarrow$ arrival at installation points $\rightarrow$ removal from guide rope for installation $\rightarrow$ fastening of glass clamps, and fixation of glass completed $\rightarrow$ repeat step 4 to step 8 .

Since the system glass is hyperbolic glass, they cannot be installed in rows but from up to down in the horizontal direction. After the glass in the horizontal direction is installed, those for the next horizontal direction should be installed. The electric hoist should be transversely moved as needed during installation.

First, the fabricated arc welded steel pipe keel at the base is installed according to the drawings and setting-out requirements. During installation, the arc welded steel pipes are installed by manual transfer, without the need for the lifting equipment. 
After the glass is transported to the second-floor roof, it is moved manually below the installation positions, installed with the platform of scissors and hoisted by the manual hoist. The glass is bound with the special lifting sling. During lifting of the glass, the platform installation staff should assist in controlling the sway of glass. When the glass is lifted to the installation positions, the platform of scissors is moved to a proper position for installation. After firm installation, the lifting system can be removed then.

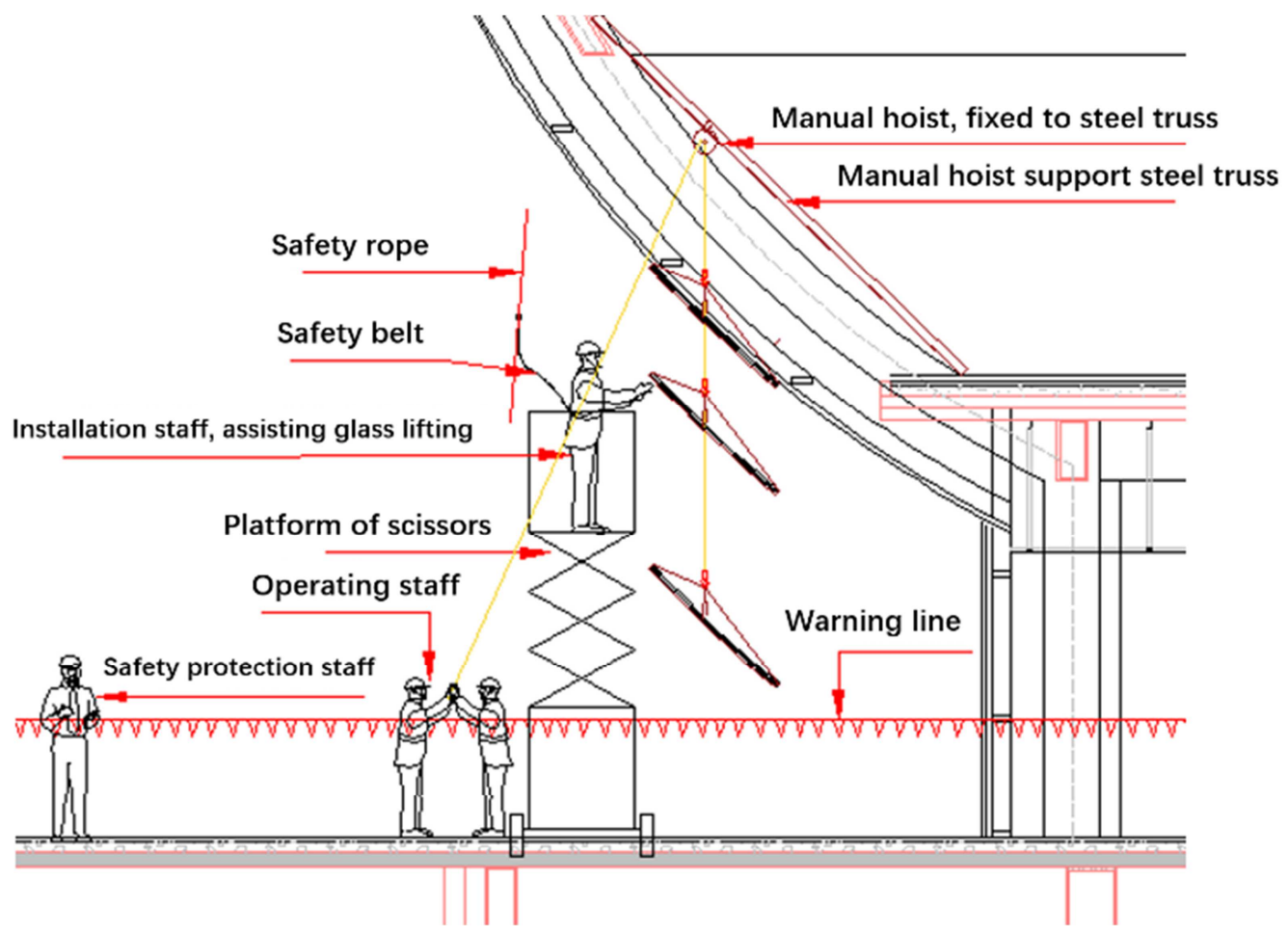

Figure 10. Schematic of glass lifting and installation.

\section{Quality Control}

The hyperbolic glass has very high requirements for installation accuracy. It is critical to smoothly install glass. In the entire process at the construction phase, the deformation control and review must be conducted. After completing the installation of the base keel and point support clamps, the entire base and clamps need to be measured. If they are not compliant with the measurement requirements, an adjustment should be made to the item until the required technical parameters of the hyperboloid are satisfied [15].

The welders should work with certificates. The welding work should conform to the welding process specifications and relevant national regulations, so as to ensure the welding quality at the base.

\section{Conclusions}

The bowl-shaped hyperbolic glass curtain wall installation methods are controlled strictly in accordance with the specifications in terms of in-depth design, utilization of BIM technology, measurement and setting out, production and processing quality, field installation, testing and inspection, thus ensuring the field safety and orderly construction, and the feasibility and safety of equipment erection for working at heights, and providing reference for the curved shape building curtain wall in the future.

\section{References}

[1] Geng Lingpeng, Li Jianming and Chen Jianhang. Construction Technology for Straight and Distorted Glass Curtain Wall in Super Tall Building [J]. Building Construction, 2011, 33 (07): 577-578.

[2] Zhang Hai. The Key Technology of Design and Construction for Hyperbolic Mental Facade Structure of Hainan Popoli Club [J]. Architecture Technique, 2016 (6): 108-110.

[3] Xu Zengjian. Applied Research on New Technology in Architectural Curtain Wall for Public Buildings in Ningbo [D]. $X i$ 'an University of Architecture and Technology, 2015.

[4] Jiang Xianlong and Cai Minghui. Construction Quality Control for Glass Curtain Wall with Inclined Elliptic Hyperbolic Oblique Pane [J]. Construction Quality, 2014, 32 (09): 47-50.

[5] Gao Shupeng. Design and Construction of Hyperbolic Unit Glass Curtain Wall in Complex Spaces [J]. Zhejiang Construction, 2013, 30 (07): 41-43+47.

[6] JGJ113-2015, Technical specification for application of architectural glass [S]. Beijing: China Architecture \& Building Press, 2016.

[7] GB/T21086-2007, Curtain wall for building [S]. Beijing: Standards Press of China, 2007. 
[8] Zhang Li. Study on the construction control of glass curtain wall [J]. Construction Materials \& Decoration, 2018, No. 533 (24): 34

[9] JG/T216-2007, Division unit panel curtain wall [S]. Beijing: China Architecture \& Building Press, 2008.

[10] JGJ102-2003, Technical code for glass curtain wall engineering [S]. Beijing: China Architecture \& Building Press, 2004.

[11] JGJ/T139-2001, Standard for testing of engineering quality of glass curtain walls [S]. Beijing: Standards Press of China, 2004.
[12] Ma Quan, Li Gensheng, Bao Guangqing et al. Building Technology for Cable-Truss Type Hyperboloid Glass Curtain Wall [J]. Building Construction, 2014 (12): 1375-1377.

[13] Bo Yufei, Construction technique of point supported glass curtain wall in projects [J]. Construction Science and Technology, 2017 (19): 154-155.

[14] GB50009-2012, Load code for the design of building structures [S]. Beijing: China Architecture \& Building Press, 2012.

[15] JGJ/T324-2014, Standard for test method of building curtain wall engineering [S]. Beijing: China Architecture \& Building Press, 2014. 